\title{
Interpreting the Procyclical Productivity of Manufacturing Sectors: Can We Really Rule Out External Effects?
}

\author{
Miguel Jiménez \\ (OECD) \\ and \\ Domenico J. Marchetti(*) \\ (Bank of Italy)
}

This version: 28 January 2000

\begin{abstract}
Explaining procyclical productivity is crucial for any theory of the business cycle. Recent contributions have focused on the dynamic implications of persistent aggregate fluctuations on sectoral productivity. Given a permanent innovation in aggregate output, variations of labor (or capital) utilization may have only a transitory effect on measured productivity, whereas external effects should produce permanent effects. We find that persistent aggregate fluctuations have a permanent effect on sectoral productivity of four-digit U.S. manufacturing industries. We discuss a number of alternative explanations of this evidence. Whereas our findings are unlikely to be due to market power and increasing returns, they are consistent with simple models with external effects or temporal agglomeration.
\end{abstract}

Keywords: Procyclical productivity; Externalities; Labor hoarding.

JEL classification: C22; D24; E32.

(*) We thank Ricardo Caballero, Fabio Canova, Douglas Holtz-Eakin, Jordi Galì, Lars P. Hansen, Argia Sbordone and, especially, Robert Waldmann for helpful discussions or comments at different stages of our research. The usual caveats apply. We are also grateful to seminar participants at Cornell University, EUI (Florence) and the 1999 EEA meeting in Santiago de Compostela. Data were kindly provided by Eric Bartelsman and Robert Hall. The views expressed here are those of the authors and do not necessarily reflect those of OECD or the Bank of Italy. 


\section{Introduction}

In a recent article, Sbordone (1997) proposed an innovative approach to the empirical assessment of the sources of procyclical productivity of manufacturing sectors. The main feature of her model, which overcomes some of the main limitations of previous contributions to the literature, is dynamics. In order to disentangle the effects on productivity of externalities from those of labor hoarding, Sbordone derives the dynamic implications of both, and compares them with data for U.S. manufacturing industries. She finds that the observed relationship between aggregate activity and sectoral productivity over time is consistent with the existence of cyclical variations in the rate of labor utilization, whereas there is no sign of external effects. In this paper we replicate her approach in a more general framework and with more disaggregated data, and obtain very different results.

Sbordone's finding, and in general the results of the burgeoning empirical literature on procyclical productivity, are crucial for business cycle theory. The stylized fact that labor productivity (as well as total factor productivity) is positively correlated with economic fluctuations, contrary to the prediction of the standard assumption of diminishing returns, has been known at least since the sixties. ${ }^{1}$ The traditional explanation of procyclical productivity is based on labor hoarding. Because of adjustment costs in hiring and firing, firms hoard labor during slumps; the fluctuations of measured productivity over the cycle are therefore mainly the result of unobserved effort variations (see for example Solow, 1964). ${ }^{2}$ This explanation identifies cyclical variations in the rate of utilization of labor (and, analogously, capital) as a key mechanism for the transmission of shocks within the economy, as in the business cycle models of Rotemberg and Summers (1990), Burnside and Eichenbaum (1996), Basu and Kimball (1997) and King and Rebelo (1999). An alternative explanation of procyclical productivity, suggested by Robert Hall (1988 and 1990), is based on the existence of increasing returns to scale in production, within or without the firm. This explanation is

\footnotetext{
${ }^{1}$ See Hultgren (1960); for recent evidence on U.S. manufacturing, see for example Sbordone (1997).

${ }^{2}$ Empirical references include Sims (1974), Fay and Medoff (1985) and Shea (1992).
} 
consistent with models of economic fluctuations where economies of scale or externalities lead to multiple equilibria, such as in the work of Murphy et al. (1989) or Baxter and King (1991). ${ }^{3}$

The investigation of the productivity puzzle is therefore closely linked to the issue of the empirical relevance of the different models of the business cycle. ${ }^{4}$ Unfortunately, the measurement of labor hoarding (and, more in general, of factor hoarding), on the one hand, and external effects, on the other, has proven to be very difficult. This is not surprising, since none of these phenomena are directly observable. Furthermore, indirect measures are far from unambiguous. With regard to the empirical assessment of effort variations, economists have used either survey data (Fay and Medoff, 1985) or proxies such as accident rates (Shea, 1992, and Jun, 1998), hours per employee (Abbott, Griliches and Hausman, 1988) or overtime hours (Caballero and Lyons, 1992). With regard to productive externalities, the first evidence was provided in a controversial article by Caballero and Lyons (1992). ${ }^{5}$ They found that returns to scale are higher for the whole manufacturing sector than for two-digit industries, and that, if aggregate output is included in sectoral production function regressions, it has a positive and significant coefficient. They interpreted these findings as evidence of external effects. However, Basu and Fernald (1995) have shown that their results could be spuriously induced by the use of valued added data with imperfect competition (see also Marchetti, 1994). More importantly, the statistical significance of aggregate variables in production-function regressions at sectoral level has been given a number of alternative explanations in the literature, including effort variations (Bernanke and Parkinson, 1991), the use of intermediate goods in production (Basu, 1995), cyclical variations in the utilization of capital (Burnside et al. 1995, and Burnside, 1996) and aggregation effects (Basu and Fernald, 1997). Sbordone (1997) contributes to this literature, and argues that aggregate variables in such regressions act as a proxy for future industry conditions, which are in turn linked to current decisions on hiring and firing and effort variations.

\footnotetext{
${ }^{3}$ See also Cooper and John (1988), Boldrin and Rustichini (1994) and Farmer and Guo (1994).

${ }^{4}$ There are also explanations of procyclical productivity based on technological stocks, such as those provided by real business cycle models. Following Sbordone (1997), in this paper we do not focus on them. However, given the specifications of our model, as well as the use of demand-side instrumental variables, we believe that the analysis is reasonably robust to the existence of technological shocks (see next section).

${ }^{5}$ See also Caballero and Lyons (1989 and 1990), and Bartelsman et al. (1992).
} 
What is most interesting in Sbordone's contribution, in our opinion, is that she focused on the dynamic effects on productivity of labor hoarding and productive externalities, and provided a framework for their assessment. This is a significant improvement in the empirical literature of procyclical productivity, since the two different explanations are almost impossible to distinguish within a "static" analysis, as is clear from the controversial interpretation of aggregate variables in traditional production-function regressions (leaving aside the collinearity problems which arise in estimation). Instead, the dynamic implications of the two explanations are very different, which makes them distinguishable on empirical grounds. Sbordone's intuition is the following. Consider one common interpretation of the externality assumption, according to which the output of a given firm or sector is positively affected, ceteris paribus, by the level of aggregate activity, through transaction or thick-market externalities due to easier matching among agents during expansions (Diamond, 1982). ${ }^{6}$ To the extent that fluctuations in aggregate output are persistent, the effect on sectoral productivity via externalities should be persistent as well. In other words, with external effects a permanent increase in aggregate output should permanently increase the level of productivity. Conversely, the effect of effort variation on productivity is only temporary. In fact, if there is a permanent increase in aggregate activity, it can be accomodated only temporarily by an increase in labor effort, since after one or more periods effort has to return to its "normal" level, and the size of the work force has to be adjusted to the new level of activity. Therefore, the impact of effort variations on productivity and that of externalities can be disentangled by looking at the impact of persistent output innovations on the level of productivity over time. By applying her model to value added data of two-digit U.S. manufacturing, Sbordone found that aggregate activity has a significant contemporaneous effect on sectoral productivity, and that this effect completely vanishes as time passes. She therefore ruled out the existence of external effects, and concluded that the observed dynamic response of productivity to aggregate activity could be rationalized only on the basis of labor hoarding effects. Further findings obtained with production-function regressions using lagged values of sectoral inputs and aggregate activity growth confirmed this interpretation.

\footnotetext{
${ }^{6}$ For models which incorporate this assumption, see for example Cooper and Haltiwanger (1993). For a review
} 
This paper re-examines Sbordone's results, by applying an extended version of her approach to a highly disaggregated panel data set. Two main modifications are made. First, we extend the original value added model to the more general framework of gross output production, thus avoiding potential model misspecification problems arising from the lack of separability conditions (they typically do not hold in U.S. data; see Jorgenson et al. 1987). Second, we apply our analytical framework to the data of four-digit U.S. manufacturing industries (Bartelsman and Gray, 1996), thus significantly reducing the impact on the estimates of aggregation effects, such as those emphasized by Basu and Fernald (1997). Appropriate corrections have been made to the Bartelsman and Gray data on revenue shares, in order to address some limitations pointed out in the literature (see Norrbin, 1993). Like Sbordone, we find a significant contemporaneous effect of aggregate activity on sectoral productivity, which diminishes over time. Contrary to her results, however, a significant portion of this effect is found to be persistent, suggesting the existence of external effects. Alternative explanations of our result are also considered, including increasing returns and market power, but they cannot fully explain the evidence. On the other hand, we find that the use of data disaggregated at the four-digit SIC level, instead of the two digit level typically used in the literature, is crucial in explaining the difference between the results presented here and those obtained in her paper. Finally, production-function regressions reported in the appendix confirm that both labor hoarding and externalities seem to play a role in the transmission of shocks over the cycle, not only the former.

The paper is organized as follows. Section 2 introduces the model, derived from Sbordone (1997), and discusses the impulse response of sectoral productivity to aggregate innovations. The next section describes the data used. Section 4 presents the estimated impulse response of sectoral productivity to aggregate fluctuations, discusses alternative explanations of the evidence found and investigates the source of the difference between this evidence and that obtained by Sbordone. Conclusions follow. The appendix presents the results obtained with production-function regressions.

of models based on macroeconomic complementarities, see Cooper (1997); a few examples of temporal agglomeration are in Hall (1991). 


\section{The Model}

The model is a simple generalization of that proposed by Sbordone (1997), where the methodology is described in detail; discussion here is limited to the main features of the approach. Consider the following production function, in which sectoral gross output $Y_{i t}$ is produced using sectoral capital $K_{i t}$, labor $L_{i t}$ and materials $M_{i t}$ :

$$
Y_{i t}=F\left(K_{i t}, L_{i t} \Theta_{i t} Y_{A t}^{\delta_{i}}, M_{i t}\right)
$$

where $\Theta_{i t}$ is a measure of exogenous sectoral technical progress and $Y_{A t}$ is output in the whole manufacturing sector. If $\delta_{\mathrm{i}}>0$, the current level of aggregate activity positively affects sectoral productivity, through an external effect. The externality may take the form of transaction or thickmarket effects, as in the Diamond's (1982) model, or high-frequency knowledge and learning spillovers (in this case past values of aggregate activity would also have an effect on sectoral output). ${ }^{7}$ Equation (1) is the same as in Sbordone (1997), except that output is measured by gross production rather than value added, and intermediate goods are included among inputs. The value added production function is a special case of the gross output one, and is frequently used by economists because the corresponding data are more easily available. However, the value added representation is valid only if the capital-labor aggregate is used in fixed proportions with materials, a condition which is often rejected by the data (see Jorgenson et al., 1987, for a detailed study of U.S. two-digit manufacturing industries).

Following Bernanke and Parkinson (1991) and Sbordone, we allow for a variable rate of utilization of labor by modeling labor input $L_{i t}$ as the product of worked hours and unobservable effort - i.e. $L_{i t}=E_{i t} H_{i t}$, where $E_{i t}$ is effort and $H_{i t}$ is hours. By assuming a standard neoclassical production function and taking logarithms and differences, equation (1) becomes:

$$
\Delta y_{i}=\alpha \Delta k_{i}+\beta\left(\Delta h_{i}+\Delta e_{i}+\Delta \theta_{i}+\delta_{i} \Delta y_{\mathrm{A}}\right)+\gamma \Delta m_{i},
$$

\footnotetext{
${ }^{7}$ For example, Baxter and King (1991) assume thick-market externalities.
} 
where lowercase letters denote logarithms and $\alpha, \beta$ and $\gamma$ represent the elasticity of output with respect to capital, labor and materials, respectively. As is well-known, the sectoral gross output Solow residual $S R_{G O i}$ is measured by:

$$
S R_{G O i}=\Delta y_{i}-\left(a_{i}^{K} \Delta k_{i}+a_{i}^{L} \Delta h_{i}+a_{i}^{M} \Delta m_{i}\right)
$$

where $a^{K}, a^{L}$ and $a^{M}$ are the revenue shares of capital, labor and materials, respectively; if firms are price takers and their technologies are characterized by constant returns, the revenue shares are equal to the output elasticities. Maintaining this assumption, it can be easily shown that the Solow residual co-moves with both effort variations and, if $\delta_{\mathrm{i}} \neq 0$, aggregate activity:

$$
S R_{G O i}=a_{i}^{L}\left(\Delta e_{i}+\Delta \theta_{i}+\delta_{i} \Delta y_{A}\right)
$$

As it was mentioned in the introduction, however, neither labor effort nor external effects are directly observable (the latter can only be approximated through a function of aggregate output). Furthermore, if labor hoarding occurs, sectoral labor effort is positively correlated with aggregate cyclical indicators (including manufacturing output) for a number of reasons, pointed out by Bernanke and Parkinson (1991). For example, the mix of effort increase and new hiring adopted by a firm faced by demand increases is affected by the slackness conditions of the economy-wide labor market. Also, to the extent that demand fluctuations are due to, respectively, economy-wide cyclical and sectoral factors, they are likely to have different persistence properties, and firms' hiring policies will respond differently. Aggregate activity can therefore serve as a signal of the degree of persistence of a given sectoral demand shock, and may consequently convey information on the sectoral rate of labor utilization. ${ }^{8}$ Indeed, the closest proxies of labor effort, including the series of accident rates, are known to be highly cyclical (Shea, 1992). Because of the contemporaneous correlation between the rate of labor utilization and aggregate cyclical variables, it is almost impossible to discriminate empirically the effect on productivity of effort variations from that of externalities, within a static analysis. Not surprisingly, the significance of aggregate variables in production-function regressions has been given a number of different interpretation in the literature, 
as pointed out in the introduction. However, a dynamic analysis can offer useful insights, as explained by Sbordone (1997) and summarized below.

Consider the impact of highly persistent economic fluctuations on the level of sectoral productivity (which is the cumulate of the Solow residual as defined by equation 4). If externalities occur, the contemporaneous effect on $S R_{G O i}$ of an increase of aggregate activity $\Delta y_{A}$ is positive, and measured by $\delta \Delta y_{A}$. If a portion $k$ of the increase of aggregate activity is permanent, the long term impact will be as large as $k \delta \Delta y_{A}$. In other words, persistent economic fluctuations need to raise the level of productivity permanently. In the extreme case in which $k$ is equal to one and there is no labor hoarding, the long-term impact would be as large as the contemporaneous one.

Consider, on the other hand, the very different dynamic pattern of the effect of persistent aggregate innovations on sectoral productivity via labor hoarding. The contemporaneous effect is typically positive, since firms respond to a demand increase with a mix of new hiring and a more intense use of the labor force available. The proportions of the mix will depend, among other things, on the expected degree of persistence of the demand increase. In any case, however, after one or more periods, effort has to return to its "normal" level, because of its stationary nature, regardless of the evolution of demand (clearly, if effort could be permanently increased, firms would have already raised it, with a corresponding cut in the labor force). The effect on productivity is therefore inherently short-lived, since the labor force will adjust to the new level of output and effort will gradually return to its original level. If there are no external effects at all, the long-term effect of persistent fluctuations on productivity is zero, since productivity will return to its original level too, after the initial increase. If both external effects and labor hoarding occur, a combination of the two dynamic patterns described will be observed. That is, immediately after the aggregate shock productivity will be pushed upwards by both effort increase and external effects. After the first period, only the effect of externalities will keep its strength (to the extent that the output innovation is permanent) while labor effort will start to diminish. Accordingly, the level of productivity will also

\footnotetext{
${ }^{8}$ Sbordone (1996 and 1997) claims that this is the role of aggregate variables in sectoral production function regressions (see the appendix of this paper).
} 
decrease. After enough time, labor effort will be back at its original level, but not productivity, which will have been permanently raised by the external effects.

Accordingly, Sbordone suggests a simple empirical test, which consists in observing the dynamic response of sectoral productivity to aggregate fluctuations in U.S. manufacturing and comparing it with the predictions of economic theory. The data used in this study and the results are presented in the following two sections.

\section{The Data}

Most of the data have been obtained from the large data set developed by Wayne Gray at NBER, which covers all U.S. four-digit SIC level manufacturing industries, in the period 1958-84 (see Bartelsman and Gray, 1996, for the most recent update). The main source for this data set is the Annual Survey of Manufacturers, conducted by the U.S. Census Bureau. Gross output is the value of shipments plus inventory change. Intermediate inputs include materials and energy, but exclude purchased services, therefore resulting in an underestimation of total intermediate inputs. Data on capital refer to both structures and equipment.

The detail of our dataset allows us to compute sectoral Solow residuals by using data on two different labor inputs - i.e., production worker hours, and the number of non-production workers (unfortunately, we do not have data on non-production worker hours). ${ }^{9}$ However, Gray's data on the compensation of labor input underestimate true labor compensation because they do not include Social Security benefits and the pay of employees in auxiliary units, who account for as much as 10 per cent of total employees. Therefore, if we used Gray's original data, the labor elasticity of output would be underestimated in the computation of the Solow residual, thus introducing a potential bias in our results (see Norrbin, 1993, on this problem with regard to the estimation of markups). In order to avoid this, we adjusted Gray's four-digit labor compensation data by using two-digit figures from

9 That is, the Solow residual used in this study is actually measured by a slightly different version of equation (3): $S R_{G O i}=\Delta y_{i}-\left(a_{i}^{K} \Delta k_{i}+\alpha_{i}^{L_{1}} \Delta h_{i, 1}+\alpha_{i}^{L_{2}} \Delta h_{i, 2}+a_{i}^{M} \Delta m_{i}\right)$, where $\Delta h_{\mathrm{i}, 1}$ and $\Delta h_{\mathrm{i}, 2}$ are the logarithmic differences of, respectively, production worker hours and the number of non-production workers. Revenue shares are also defined accordingly. 
U.S. National Income and Production Accounts (NIPA) and assuming that the labor compensation data for four-digit industries within each two-digit sector are uniformly underestimated.

\section{The Results}

We model the joint dynamics of our main variables - the rate of growth of aggregate manufacturing output, $\Delta y_{\mathrm{A}}$, and sectoral productivity, $\Delta S R_{G O i}$ - as a stationary two-variable vector autoregressive process of order one. More formally, let $X(\mathrm{t})$ be the vector $\left(\Delta y_{\mathrm{A}}, \Delta S R_{G O i}\right)$, and $u(\mathrm{t})$ a two-dimensional white noise process. We assume that $X(\mathrm{t})$ follows a stationary stochastic process, with the canonical moving average representation:

$$
X(t)=\phi(0) u()+\phi(1) u(t-1)+\ldots=\sum_{i=0}^{\infty} \phi(i) u(t-1)
$$

where $\operatorname{Var}(u)=\Omega$ and $\phi(0)=I \cdot{ }^{10}$ Such a process can be also expressed in terms of orthogonal or fundamental residuals. Let $e(\mathrm{t})$ be the vector $\left(e_{\mathrm{a}}, e_{\mathrm{s}}\right)$, where $e_{\mathrm{a}}$ and $e_{\mathrm{s}}$ are innovations in, respectively, aggregate output and sectoral productivity, and are independent of each other. Accordingly, $X(\mathrm{t})$ can be expressed as:

$$
X(t)=\Theta(0) e(t)+\Theta(1) e(t-1)+\ldots=\sum_{i=0}^{\infty} \theta(i) e(t-1)
$$

with $\operatorname{Var}(e)=\mathrm{I}$, and where $\Theta(\mathrm{i})=\phi(\mathrm{i}) P$, for $\mathrm{i}=0,1,2 \ldots ; e(\mathrm{t})=P^{-1} u(\mathrm{t})$, and the matrix $P$ has to satisfy $\Omega=P P^{\prime}{ }^{11}$

Impulse responses are generated by fitting a first-order autoregressive model to the vector $X(\mathrm{t})$. The errors are orthogonalized through a lower Cholesky decomposition of the residual covariance matrix $\Omega$. This corresponds to assuming that the growth of aggregate output may affect sectoral productivity growth contemporaneously, but not vice versa. Although quite simple, this seems a reasonable assumption, given the limited size of each industry (four-digit SIC level) vis-à-vis the whole manufacturing sector. It is also consistent with the assumption that technological shocks

\footnotetext{
${ }^{10}$ For simplicity, we omit the vector of means from the representation.

11 Note that the disturbances $e(t)$ are mutually uncorrelated by construction. See, for example, Luetkepohl (1991). Note also that $P$ is not uniquely defined, up to this point.
} 
are uncorrelated across sectors; though controversial, this is a reasonable feature of true technological shocks in manufacturing, according to some of the empirical evidence in the literature_(see Long and Plosser, 1987). In any case, like Sbordone, we also provide estimates obtained with demand instruments in order to minimize the effects of aggregate technology shocks.

We estimated the model by pooling all four-digit industries. In order to get an insight on sectoral patterns, we also estimated the model separately for each two-digit sector, by pooling the four-digit industries belonging to each sector. In both cases, the omission of individual industry effects results in biased and inconsistent estimates of the parameters. In this respect, at least two alternative estimating procedures are available. If the number of observations is large enough, one can treat individual effects as constants to be estimated, and use the familiar dummy variables leastsquares estimator, or within-estimator (Hsiao, 1986). The other procedure - which is necessary when the number of observations is small, and the within-estimator is therefore inconsistent - consists in differencing the original equation, thus eliminating any (constant) individual effects, and applying instrumental variables estimation (Holtz-Eakin et al. 1988). Since the specification of our model is in first differences (rates of growth), differencing the variables once more could lead to all sorts of problems induced by overdifferencing. Moreover, we have as many as twenty-six observations, quite a large number for panel data. We therefore used the dummy variables least-squares estimator. ${ }^{12}$ It could be argued that the relationship between aggregate fluctuations and productivity is driven by common technological shocks: we therefore also used demand-side instruments, as already mentioned, to obtain results which are robust with respect to this kind of objection. As regards the choice of instruments, we followed the literature (Hall, 1988); the instrumental variables are the political party of the president and the rate of growth of the oil price and defense expenditure, and their first and second lag.

Figure 1 reports the impulse response of the productivity level to a unit innovation in aggregate output, for the whole manufacturing sector and for some two-digit industries, selected as

\footnotetext{
${ }^{12}$ In order to capture a possible change in the trend of the variables after the oil crisis (see Perron, 1989), we considered the inclusion of two dummies for each industry, one for the period pre-1973 and another for the period post-1973. The substance of the results did not change.
} 
those where productivity displays a more clear cyclical pattern (standard error bands, computed according to Luetkephol, 1991, are shown by solid lines). The point estimates of the contemporaneous and long-run impulse responses are reported in Table 1, for both aggregate output and sectoral productivity. Overall, the results are quite similar to those obtained by Sbordone (1997), with one crucial exception which will be discussed below. First, aggregate innovations turn out to be highly persistent. In fact, the long-run response of aggregate output is relatively high. Second, sectoral productivity increases after an aggregate shock. More precisely, a unit standard error aggregate shock, which corresponds to a 6 per cent increase of aggregate output, is accompanied in the first period by an increase of almost 2 per cent in the productivity level, presumably because of both effort variations (due to less than perfect adjustment of the work force) and external effects. Third, productivity declines, more or less smoothly, in the following periods (Solow residuals are negative). However, contrary to Sbordone's finding, productivity does not return to its original level, but converges to a new, higher level. In other words, persistent innovations in aggregate output are found to have a permanent positive effect on the level of productivity. Since this result is also obtained using demand-side instrumental variables, it cannot be explained by aggregate technological shocks. Neither can it be attributed to effort variations, since effort cannot be increased permanently. On the other hand, internal returns are ruled out by the estimates of production-function regressions reported in the appendix, according to which returns to scale are slightly decreasing; such evidence is consistent with that of most studies at the firm or plant level, which find essentially constant returns to scale (see for example Baily et al. 1992, where most estimates are slightly less than one). ${ }^{13}$ Therefore, consistently with the criterion proposed by Sbordone, the explanation of the permanent effect on productivity of aggregate innovations calls for the existence of external effects, for example in the form of the transaction or thick-market effects described by Diamond (1982).

An alternative explanation of the correlation between the Solow residual and activity growth is market power. Under imperfect competition, revenue shares do not correspond to output elasticities, and accordingly the Solow residual defined by equation (3) does not represent only

\footnotetext{
${ }^{13}$ In addition, approximately constant returns to scale are needed to justify the large observed dispersion of plant
} 
productivity growth. Therefore, the Solow residual will be correlated with output in a way that depends on the markup of price to marginal cost. This correlation has been used by Hall (1988) to estimate the level of markups for manufacturing sectors in the U.S. However, we do not believe that market power can explain our results, for the following reasons. First, the sectoral pattern of the results (described below), shows that if the markup does play a role in driving the results, it is limited. In fact, a strong long-run response of the productivity level to aggregate shocks has been also found in sectors, such as those producing furniture, machinery, primary metals and metal products, which are not highly concentrated and do not display significant markups according to any measurement technique or approach used (see, for example, the coefficient estimates provided by Norrbin, 1993, and the measures based on Census data reported by Domowitz et al., 1988). Second, our finding of external effects is confirmed by the results of the production-function regressions reported in the appendix, which are derived from Sbordone's structural model, within a framework which is robust with respect to imperfect competition. It could be argued that, in order to control for markups, we should have used properly adjusted measures of the Solow residual (see Hall, 1990). ${ }^{14}$ However, the estimation of markups carried out by Hall has its shortcomings (see Breshanan, 1989). In addition, and more crucially, there is not much sense in using Solow residuals corrected for the cycle or markups when investigating the existence of externalities and labor hoarding. In fact, imperfect competition, externalities and labor hoarding can be viewed as three different explanations of the correlation between productivity and the business cycle. In the corrected residuals the covariation with output, due to any of the sources mentioned, would disappear altogether (see Jiménez, 1997).

In order to investigate the sectoral detail of the productivity response, we estimated the model separately for each two-digit sector, by pooling the four-digit industries belonging to each of them. Given the fairly reasonable homogeneity among the cross-section units involved, such regressions should yield quite accurate estimates. The estimates of both first-period and long-run responses of

\footnotetext{
size within industries.

${ }^{14}$ This is the solution chosen by Malley et al. (1998), who study the dynamic relationship between employment and productivity in U.S. manufacturing sectoras by using cyclically-adjusted Solow residuals. They find that
} 
productivity to aggregate shocks are reported for each two-digit sector in Table 2. The results although they vary widely across sectors - largely confirm the evidence found with the pooled regression.

Overall, the null hypothesis of a zero long-run response is rejected in respectively thirteen and twelve industries out of nineteen, at the five per cent one-tail significance level, on the basis of OLS and IV estimates. However, by assessing the test statistics for each industry separately, the overall probability of rejecting a true null hypothesis increases with the number of industries, and is significantly higher than the desired significance level. To avoid this, we use the sequential Bonferroni approach suggested by Holm (1979), and test the null hypothesis for each industry with an overall significance level $\alpha$ of five per cent. That is, we consider the industry with the highest tstatistics - i.e., in both sets of estimates, industry 35 (machinery) - and set the significance level equal to $\alpha / \mathrm{n}$, where $\mathrm{n}$ is the number of industries (nineteen). It can be seen that $\alpha / \mathrm{n}=.00263$, which is significantly smaller than the original .05 . Since the one-tail p-value corresponding to 12.3 (the $t$ value of machinery, IV estimate) is lower than .00263 , we reject the null hypothesis for industry 35 . The sequential Bonferroni procedure requires that we examine the industry with the second-highest tstatistic, set the significance level equal to $\alpha /(n-1)$, perform the test, and so on, until we are unable to reject the null hypothesis for one sector. This procedure allows us to perform each test consistently with the desired overall significance level. In our case, with OLS estimates, the procedure stopped at the twelfth step, since we were unable to reject the null hypothesis for the twelfth industry considered, i.e. transportation equipment. With IV estimates, the procedure stopped at the tenth industry considered, again transportation equipment. Therefore, the number of sectors with a significant long-run response is respectively eleven and nine out of nineteen, on the basis of OLS and IV estimates; the relevant sectors are starred in the table. The sets of sectors with a significant response, corresponding to each estimator, mostly coincide, indicating that the results are very robust 
across estimators. The sectors involved are mainly durable goods industries, which are those where production and productivity usually fluctuate the most. ${ }^{15}$

To sum up, we have found strong evidence of a positive long-run response of productivity to persistent innovations in aggregate activity. Although we have used an extended version of Sbordone's (1997) model, our results are very different from hers. It is important to understand why this is the case, or at least to identify the sources of the discrepancy. Two possible differences between her empirical analysis and that carried out here concern (i) the disaggregation level of the data and (ii) the use of value added rather than gross output data.

In order to obtain evidence on the first issue, i.e. the potential effects of aggregation, we constructed two-digit data from our data set, by aggregating the data of four-digit industries belonging to each two-digit sector, for each variable. We then estimated the model with the rate of growth of aggregate manufacturing gross output and sectoral (two-digit) gross output Solow residuals. The results are reported in Table 3a. Whereas aggregate innovations still have a large contemporaneous impact on sectoral productivity, the evidence of a persistent effect has completely disappeared. In fact, the coefficient of the long-run response is found to be very low and not statistically different form zero, in both OLS and IV estimates. In order to investigate the aggregation bias which arises when using value added data, as Sbordone does, we constructed value added data from Bartelsman-Gray's four-digit data, by subtracting intermediate goods from gross output, and calculated value added Solow residuals. We then aggregated the data by two-digit industry, and estimated the model with the rate of growth of aggregate manufacturing value added and sectoral (two-digit) value added Solow residuals. The estimates are considerably less precise, but the substance does not change (see Table $3 \mathrm{~b}$ ). The estimate of the contemporaneous impact of aggregate shocks on sectoral productivity is positive and larger than before, but so is the standard error. More importantly, the long-run response is not statistically different from zero with both estimators.

Taken together, these results suggest a possible explanation for the difference between the results reported in this paper and those obtained by Sbordone. ${ }^{16}$ The latter appear to be driven by

\footnotetext{
${ }^{15}$ Durable goods industries are those with SIC codes 24,25 and 32 to 39.
} 
aggregation effects (due to the use of two-digit level data), of the kind recently investigated, in the related context of estimating returns to scale, by Basu and Fernald (1997). Clearly, aggregation effects also affect the results reported in this article; however, they are likely to be less severe when using data disaggregated at the four-digit level. Employing value added data is another potential source of bias. The use of a value added framework is an analytical short-cut which is correct if and only if value added and intermediate goods are separable, i.e. linked in fixed proportions, within the production function. This condition typically does not hold in U.S. data. ${ }^{17}$

\section{Conclusions}

We find that persistent innovations in aggregate output are associated with a persistent increase in the level of sectoral productivity. This result cannot be attributed to labor hoarding or effort variations (or capital utilization, for that matter), because labor effort (and capital utilization), which is by definition a stationary variable, cannot be permanently increased, but has to return over time to its "normal" level. Also, our finding cannot be simply explained by aggregate technological shocks, since it has been largely confirmed by estimates obtained with demand instruments. Finally, the sectoral pattern of the results suggests that they are not driven by market power and increasing returns (this interpretation is confirmed by the evidence obtained with production-function regressions, reported in the appendix). On the other hand, our results are fully consistent with simple models with productive externalities, in the form of transaction or thick-market effects (see for example Hall, 1991).

The results reported here are very different from those obtained by Sbordone (1997), who did not observe any permanent effect of persistent aggregate fluctuations on productivity. In this paper

\footnotetext{
${ }^{16}$ We also investigated the effect of the use of value added data alone; to do so, we constructed value added data from the four-digit Bartelsman-Gray data, by subtracting intermediate goods from gross output, and calculated value added Solow residuals. We then estimated the model with the rate of growth of aggregate manufacturing value added and sectoral value added Solow residuals. The results support the finding of a significant long-run response of productivity to aggregate shocks, but the evidence is somewhat weaker than that obtained with gross output data, especially with OLS estimates (the t-statistic of the relevant coefficient is equal to 1.97). Overall, as in the case of the results obtained with value added data at the two-digit level, the estimates are considerably less precise.

${ }^{17}$ Moreover, Basu and Fernald have shown that value added data suffer from a different aggregation bias than gross output data. Whereas a priori it is not clear which one is larger, in estimating returns to scale with Jorgenson's data they found the value added aggregation bias to be significantly larger than the gross output one.
} 
we provide an explanation for this difference. In fact, further investigation of the data suggests that Sbordone's results are driven by aggregation effects. The data used here are more disaggregated (four-digit rather than two-digit SIC level), thus presumably reducing the importance of aggregation bias. Furthermore, we use gross output rather than value added data, thus avoiding another potential source of bias.

Investigating procyclical productivity is a very complex task, because of the several theoretical and measurement issues involved. We do not ignore or dispute the importance of unobserved factor utilization, which is almost unanimously recognized as a major source of procyclical productivity (see for example Basu et al., 1999, and King and Rebelo, 1999). However, the results presented in this paper suggest that external effects cannot be dismissed as potential channel for the transmission of shocks over the business cycle, and that explanations based entirely on cyclical variations of factor utilization might miss some basic economic mechanism behind procyclical productivity. The search for further evidence on the relevance of high-frequency productive externalities will benefit from (i) the use of firm-level data, in order to avoid aggregation bias, and (ii) a flexible analytical approach, explicitly allowing for variable factor utilization, imperfect competition and increasing returns. Given the implications for theoretical models of the business cycle and the increasing importance of models based on macroeconomic complementarities, future empirical research in this direction seems worth pursuing. 


\section{References}

Abbott, T., Z. Griliches and J. Hausman (1988), "Short-run movements in productivity: Market power vs. capacity utilization.” Manuscript.

Baily, M.N., C. Hulten and D. Campbell (1992), "Productivity Dynamics in Manufacturing Plants." Brookings Papers on Economic Activity, Microeconomics: 187-249.

Bartelsman, E.J. and W.B. Gray (1996), “The NBER manufacturing productuvity database.” NBER Technical Working Paper No. 205.

Bartelsman, E.J., R.J. Caballero and R.K. Lyons (1994), "Customer and supplier-driven externalities." American Economic Review 84: 1075-84.

Basu, S. (1995), "Intermediate Goods and Business Cycles: Implications for Productivity and Welfare." American Economic Review 85: 512-531.

Basu, S. and J. Fernald (1995), "Are Apparent Productive Spillovers A Figment of Specification Error?” Journal of Monetary Economics 36: 165-188.

Basu, S. and J. Fernald (1997), "Returns to Scale in U.S. Production: Estimates and Implications." Journal of Political Economy 105: 249-283.

Basu, S., Fernald J. and M.S. Kimball (1999), “Are Technology Shocks Contractionary?" Manuscript.

Basu, S. and M.S. Kimball (1997), "Cyclical Productivity with Unobserved Input Variation.” NBER Working Paper No. 5915.

Baxter, M. and R.G. King (1991), "Productive Externalities and the Business Cycle." Institute for Empirical Macroeconomics discussion paper No. 53 (Federal Reserve Bank of Minneapolis, Minneapolis, MN).

Bernanke, B.S. and M.L. Parkinson (1991), "Procyclical Labor Productivity and Competing Theories of the Business Cycle: Some Evidence from Interwar U.S. Manufacturing Industries." Journal of Political Economy 99: 439-459.

Boldrin, M. and A. Rustichini (1994), "Growth and Indeterminacy in Dynamic Models with Externalities." Econometrica 62: 323-342.

Bresnahan, T.F. (1989), "Empirical Studies of Industries with Market Power." In Handbook of Industrial Organization, R. Schmalensee and R. Willing, eds. (North Holland, Amsterdam).

Burnside, C. (1996), "Production function regressions, returns to scale and externalities." Journal of Monetary Economics 37: 177-201.

Burnside, C. and M. Eichenbaum (1996), "Factor-Hoarding and the Propagation of Business-cycle Shocks." American Economic Review 86: 1154-1175.

Burnside, C., M. Eichenbaum and S. Rebelo (1995), "Capital Utilization and Returns to Scale." NBER Macroeconomic Annual: 67-110.

Caballero, R.J. and R.K. Lyons (1989), “The Role of External Economies in U.S. Manufacturing.” NBER Working Paper No. 3033.

Caballero, R.J. and R.K. Lyons (1990), "Internal versus External Economies in European Industry." European Economic Review 34: 805-830.

Caballero, R.J. and R.K. Lyons (1992), "External Effects in U.S. Procyclical Productivity.” Journal of Monetary Economics 29: 209-25. 
Cooper, R. (1997), "Business Cycle: Theory, Evidence and Implications." NBER Working Paper No. 5994.

Cooper, R. and J. Haltiwanger, (1993), "Evidence on Macroeconomic Complementarities." NBER Working Paper No. 4577.

Cooper, R. and A. John, (1988), "Coordinating Coordination Failures in Keynesian Models." Quarterly Journal of Economics 103: 441-463.

Diamond, P. (1982), “Aggregate Demand Management in Search Equilibrium.” Journal of Political Economy 90: 881-94.

Domowitz, I., R.G. Hubbard and B.C. Petersen (1988), "Market Structure and Cyclical Fluctuations in U.S. Manufacturing." Review of Economics and Statistics 70: 55-66.

Farmer, R. and Guo, J. (1994), "Real Business Cycles and the Animal Spirits Hypothesis." Journal of Economic Theory 63: 42-72.

Fay, J.A. and J.L. Medoff (1985), "Labor and Output over the Business Cycle: Some Direct Evidence." American Economic Review 75: 638-655.

Hall, R.E. (1988), “The Relation between Price and Marginal Cost in U.S. Industry." Journal of Political Economy 96: 921-47.

Hall, R.E. (1990), "Invariance Properties of Solow's Productivity Residual.” In P. Diamond, ed., Growth, Productivity, Employment (MIT Press, Cambridge, Mass.).

Hall, R.E. (1991), Booms and Recessions in a Noisy Economy (Yale University Press, New Haven).

Holm, S. (1979), “A Simple Sequentially Rejective Multiple Test Procedure.” Scandinavian Journal of Statistics 6: 65-70.

Holtz-Eakin, D., W. Newey and H.S. Rosen (1988), "Estimating Vector Autoregressions with Panel Data." Econometrica 56: 1047-1070.

Hultgren, T. (1960), "Changes in Labor Costs during Cycles in Production and Business." NBER Occasional Paper No. 74.

Hsiao, C. (1986), Analysis of panel data (Cambridge University Press, Cambridge, U.K.).

Jiménez, M. (1997), Cyclical Productivity in U.S. Manufacturing (Garland Publishing, New York).

Jorgenson, D.W., F.M. Gollop and B.M. Fraumeni (1987), Productivity and U.S. Economic Growth (MIT Press, Cambridge, Mass.).

Jun, S. (1998), "Procyclical Multifactor Productivity: Tests of Current Theories." Journal of Money, Credit and Banking 30: 51-63.

King, R.J. and S. Rebelo (1999), "Resuscitating Real Business Cycles". In J.P. Taylor and M. Wodford, eds., Handbook of Macroeconomics (North-Holland, Amsterdam).

Long, J. and C. Plosser (1987), "Sectoral versus Aggregate Shocks in the Business Cycle." American Economic Review 77, Papers and Proceedings 333-336.

Luetkepohl, H. (1991), Introduction to Multiple Time Series Analysis (Springer-Verlag, Berlin).

Malley, J.R., V.A. Muscatelli and U. Woitek (1998), "The Interaction Between Business Cycles and Productivity Growth: Evidence from US Industrial Data." Discussion Paper in Economics No. 9805 (University of Glasgow).

Marchetti, D.J. (1994), "Procyclical Productivity, Externalities and Labor Hoarding: A Reexamination of Evidence from U.S. Manufacturing." European University Institute Working Paper in Economics No. 1994/13 (EUI, Florence, Italy).

Murphy, K.M., A. Schleifer and R.W. Vishny (1989), "Building Blocks of Market Clearing Business Cycle Models." NBER Macroeconomics Annual: 247-287. 
Norrbin, S.C. (1993), "The Relation between Price and Marginal Cost in U.S. Industry: A Contradiction." Journal of Political Economy 101: 1149-1166.

Perron (1989), "The great crash, the oil price shock, and the unit root hypothesis." Econometrica 57: 1361-1401.

Rotemberg, J. and L. Summers (1990), "Inflexible Prices and Procyclical Productivity." Quarterly Journal of Economics 105: 851-74.

Sbordone, A.M. (1996), "Cyclical Productivity in a Model of Labor Hoarding." Journal of Monetary Economics 38: 331-361.

Sbordone, A.M. (1997), "Interpreting the Procyclical Productivity of Manufacturing Sectors: External Effects or Labor Hoarding?" Journal of Money, Credit and Banking 29: 26-45.

Shea, J. (1992), “Accident Rates, Labor Effort and the Business Cycle." University of Wisconsin, Manuscript.

Sims, C.A. (1974), "Output and Labor Input in Manufacturing." Brookings Papers on Economic Activity: 695-735.

Solow, R.M. (1964), Draft of the Presidential Address to the Econometric Society on the Short-Run Relation between Employment and Output. 


\section{Appendix. Production-function Regressions}

After analyzing impulse responses, Sbordone (1997) studies the dynamic impact of aggregate shocks on productivity within a more structured framework. She makes use of the adjustment cost model of Sbordone (1996), which provides a structural framework for testing the effort variations hypothesis versus the external effects one. The details and steps of the model are described in both of her articles; here we summarize the intuition behind the model, and introduce the final form of the production-function regression, generalized with reference to the case of gross output production.

The basic idea of Sbordone is that aggregate variables enter sectoral production functions with a positive coefficient not because of true external effects, but rather because they help forecast the future evolution of sectoral labor; this prediction affects the level of effort required from current employees through firms' current decisions on hiring and firing. Since labor effort is typically an omitted variable in production-function regressions, its role can be indirectly captured by aggregate variables, through the channel just described. In other words, if production is only temporarily high (and no future increase of the labor force is expected), a firm faced with adjustment costs will tend to utilize its current labor force more intensively rather than expand it through new hiring. The current level of labor effort is therefore related to the firm's expectations with respect to the future growth of output and labor. If higher aggregate growth helps to forecast, ceteris paribus, lower future growth of sectoral labor, it will be associated with an increase of sectoral labor effort. Aggregate variables, in the context of production-function regressions where labor utilization is omitted, will proxy for it. Therefore, the coefficient of aggregate growth may be found to be statistically significant even if external effects do not occur.

In order to test this hypothesis, Sbordone analyzes the problem of a representative firm which has a technology such as that described by equations (1) and (2), with the assumptions that labor is costly to adjust, and that adjustment costs increase with the size of the adjustment. The total labor costs faced by the firm are a convex function of labor effort, too. The latter variable is obtained from the production function, and substituted into the firm's cost function. Firms are assumed to minimize costs. The log-linear approximation of the first-order condition around a steady-state path provides 
the basis for the empirical analysis, leading to a regression of sectoral output growth on the growth of sectoral inputs, the wage rate and aggregate output (Sbordone, 1997, pp. 37-39). Finally, aggregate variables are assumed to act as forecasting variables for future conditions of sectoral labor. The optimal decision rule for sectoral hours is assumed to be a function of capital stock and the dynamics of a vector of state variables, which include sectoral technological shocks, the growth of sectoral capital and aggregate output, and the sectoral capital-output ratio. By plugging the solution for sectoral hours into the first-order condition, one obtains a specification where the growth of sectoral output is a function of current and past values of sectoral inputs as well as aggregate output (for details, see Sbordone, 1997, pp. 39-40). The unrestricted form of this specification, which nests the two hypotheses of interest and is suitable for empirical analysis, is:

$$
\Delta y_{t}=\theta_{1} \Delta h_{t}+\theta_{2} \Delta h_{t-1}+\theta_{3} \Delta k_{t}+\theta_{4} \Delta k_{t-1}+\theta_{5} \Delta m_{t}+\theta_{6} \Delta m_{t-1}+\sum_{j=0}^{J} \varphi_{j} \Delta y_{A, t-j}+u_{t}
$$

where the sectoral index $i$ is dropped for convenience and all other variables are as defined above. ${ }^{18}$

Equation (7) is the gross output generalization of equation (10) in Sbordone (1997). It represents a reduced form of the model described by Sbordone (1996 and 1997); its coefficients are a function of the parameters of the structural model and the optimal decision rule for hours. Sbordone has formally derived the restrictions imposed upon the reduced form coefficients by the hypotheses of, respectively, labor hoarding and external effects. These restrictions are quite simple and intuitively appealing, as summarized below.

1. Under the null hypothesis of contemporaneous external effects - such as those modeled in equation (1) - and no labor hoarding, the coefficient of current aggregate output $\left(\varphi_{0}\right)$ should be significantly different from zero and positive, whereas the coefficients of the lagged values of aggregate output should be equal to zero. They may be different from zero if the external effects also occur with some delay. However, no individual coefficient associated with aggregate output should be negative.

\footnotetext{
${ }^{18} \mathrm{H}$ is measured by production worker hours.
} 
2. Under the null hypothesis of labor hoarding and no external effects, the sum of the coefficients of current and lagged values of aggregate output should be equal to zero. In fact, this sum measures the long-run effect of the dynamics of aggregate output on sectoral output; this should be a good measure of external effects, since in the long-run labor effort has to return to its "normal" level, and therefore aggregate output, in its role as proxy (or forecasting variable) for labor utilization, can have only a temporary effect on output and productivity.

Accordingly, the testing strategy has two steps. First, to determine whether some of the coefficients of aggregate output are individually significant and negative; if they are, the null hypothesis of no labor hoarding is rejected. Second, to determine whether the sum of these coefficients is equal to zero; if it is not, the null hypothesis of no external effects is rejected. Furthermore, one can also determine whether returns to scale are constant, by testing whether the sum of the coefficients of current and lagged values of sectoral inputs is equal to one. As for the results, Sbordone (1997) rejects the hypothesis of no labor hoarding, whereas she accepts that of no external effects. She also finds returns to scale to be constant (at least according to the instrumental variables estimations). We fitted equation (7) with Gray's gross output data at the four digit level. The results of the estimates and tests are reported in Table 4.

As with the estimates of the impulse responses, we report both OLS and instrumental results. With regard to sectoral inputs, the coefficients of the current growth of labor and intermediate goods are clearly significant and have the expected sign, in both OLS and IV estimates. Since the coefficients of equation (7) are a (somewhat complex) function of the parameters of the structural model, one can also rationalize the negative sign of the lagged growth of labor. ${ }^{19}$ The coefficients of the other regressors concerning sectoral inputs are not significant. The most important results, for our purposes, are those concerning the coefficients of aggregate output. As expected, the current growth of aggregate output enters the equation with a significant and positive coefficient, in both sets of estimates. Also, a lagged value of aggregate output growth is associated with a significant and negative estimate in both sets of estimates (the first lag according to OLS estimates, the second lag

\footnotetext{
${ }^{19}$ See, for example, Sbordone's interpretation of her finding of a negative coefficient of lagged capital growth.
} 
according to IV estimates). In both cases, therefore, we find evidence which leads the null hypothesis of no labor hoarding being rejected, as in Sbordone (1997). However, in contrast with her result, the sum of the coefficients of aggregate output is found to be different from zero. Thus, we find evidence consistent with the existence of external effects also within a production-function analytical framework. This result is robust across estimators. Finally, returns to scale are found to be slightly decreasing, in line with the evidence of most studies at firm level. 
Figure 1

Dynamic Response of Sectoral Productivity to a Unit Innovation in Aggregate Output
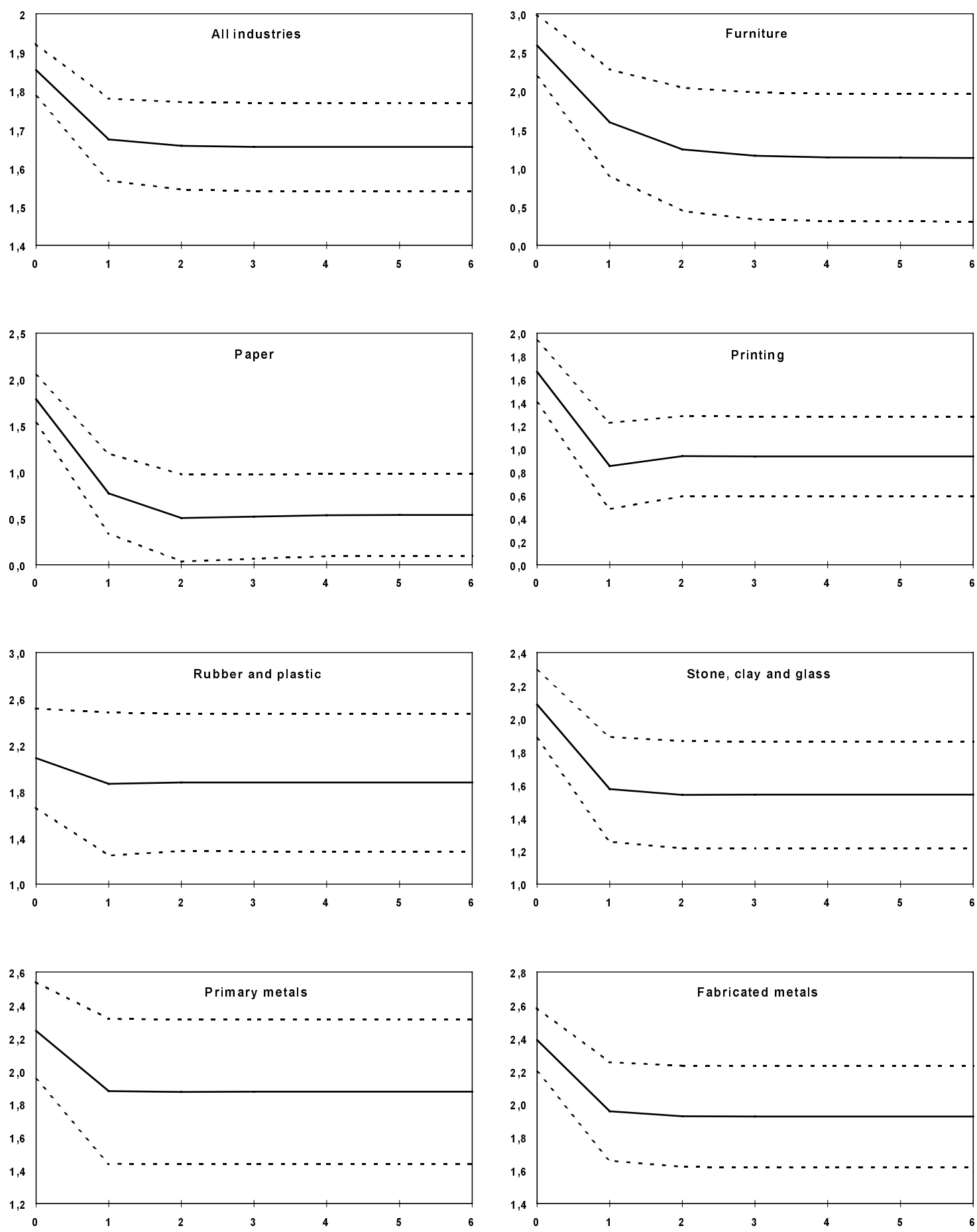


\section{Table 1 \\ RESPONSES TO AGGREGATE INNOVATIONS}

(per cent)

IV

\begin{tabular}{cccc} 
OLS & \multicolumn{2}{c}{ IV } \\
$\begin{array}{c}\text { Contemporaneous } \\
\text { response }\end{array}$ & $\begin{array}{c}\text { Long-run } \\
\text { response }\end{array}$ & $\begin{array}{c}\text { Contemporaneous } \\
\text { response }\end{array}$ & $\begin{array}{c}\text { Long-run } \\
\text { response }\end{array}$ \\
$5.90(.04)$ & $6.83(.09)$ & $5.97(.04)$ & $5.81(.07)$ \\
$1.88(.07)$ & $1.74(.10)$ & $1.85(.07)$ & $1.65(.11)$
\end{tabular}

Aggregate output

Sectoral productivity
OLS

1.85 (.07)

Note: Annual four-digit data, 1958-1984 (Gray and Bartelsman, 1996). Responses to a unit innovation in aggregate output. Instruments are the political party of the president and the rate of growth of military expenditure and the oil price, current and lagged once and twice. The standard errors of the impulse responses are estimated following Luetkepohl (1991).

\section{Table 2 \\ RESPONSE OF SECTORAL PRODUCTIVITY TO AGGREGATE INNOVATIONS}

(per cent)

OLS IV

Two-digit SIC level industry

Contemporaneous
response

$.88(.63)$
$.75(.32)$
$.96(.25)$
$-.03(.33)$
$2.56(.38)$
$1.46(.25)$
$1.61(.27)$
$2.76(.29)$
$.76(.63)$
$2.12(.42)$
$-.39(.39)$
$2.05(.20)$
$2.22(.29)$
$2.41(.19)$
$2.86(.18)$
$2.97(.21)$
$1.42(.30)$
$1.76(.33)$
$2.39(.33)$

$\begin{array}{cc}\begin{array}{c}\text { Long-run } \\ \text { response }\end{array} & \begin{array}{c}\text { Contemporaneous } \\ \text { response }\end{array} \\ 1.15(.93) & .57(.64) \\ -.05(.49) & 0.87(.33) \\ .32(.39) & .82(.26) \\ -1.61(.44) & -.27(.34) \\ 1.79 *(.55) & 2.59(.40) \\ .88(.37) & 1.79(.26) \\ 1.31 *(.40) & 1.67(.27) \\ 2.82^{*}(.46) & 2.74(.29) \\ .72(1.13) & .97(.66) \\ 2.09 *(.57) & 2.09(.43) \\ -1.03(.57) & -.60(.40) \\ 1.87 *(.30) & 2.09(.21) \\ 2.00^{*}(.39) & 2.24(.30) \\ 2.25 *(.29) & 2.39(.19) \\ 4.30^{*}(.30) & 2.76(.19) \\ 3.16^{*}(.37) & 3.03(.22) \\ 1.21(.46) & 1.36(.31) \\ 2.55^{*}(.45) & 1.68(.33) \\ 1.64 *(.47) & 2.55(.34)\end{array}$

Long-run response

21. Tobacco

22. Textile mill

23. Apparel

24. Lumber and wood

25. Furniture

26. Paper

27. Printing

28. Chemicals

29. Petroleum and coal

30. Rubber and plastic

31. Leather

32. Stone, clay and glass

33. Primary metals

34. Fabr. metals

35. Machinery

36. Electric machinery

37. Transportation equipment

38. Instruments

$2.39(.33)$

$1.85 *(.97)$

$.07(.56)$

$.73(.43)$

$-.18(.52)$

$1.13(.83)$

$.54(.45)$

$.94 *(.34)$

$3.01 *(.55)$

$-1.46(1.51)$

$1.88 *(.59)$

$.06(.54)$

$1.54 *(.32)$

$1.88 *(.44)$

$1.92 *(.31)$

$4.31 *(.35)$

$2.50 *(.40)$

$1.32(.54)$

$2.09 *(.49)$

$1.00(.50)$

Note: Annual four-digit SIC level data, 1958-1984 (Bartelsman and Gray, 1996). Response of sectoral productivity to a unit innovation in aggregate output. Instruments are the political party of the president and the rate of growth of military expenditure and the oil price, current and lagged once and twice. The standard errors of the impulse responses are estimated following Luetkepohl (1991). The starred long-run responses are those significantly positive at 5 percent aggregate level, according to the Bonferroni sequential procedure described in the text. 
Table 3

RESPONSE OF SECTORAL PRODUCTIVITY TO AGGREGATE INNOVATIONS AGGREGATION EFFECTS AND THE USE OF VALUE ADDED DATA

Contemporaneous response

$1.17(.14)$

Contemporaneous response $2.84(.47)$
OLS

OLS

(per cent)

\section{(a) Aggregation effects}

Model with aggr. manufacturing gross output and sectoral gross output Solow residuals at 2-digit level

$\begin{array}{ccc}\begin{array}{c}\text { Long-run } \\ \text { response }\end{array} & \begin{array}{c}\text { Contemporaneous } \\ \text { response }\end{array} & \begin{array}{c}\text { Long-run } \\ \text { response }\end{array} \\ .21(.35) & 1.17(.14) & .08(.42)\end{array}$

\author{
(1)
}

(b) Aggregation effects and the use of value added data Model with aggregate manufacturing value added and sectoral value added Solow residuals at 2-digit level

\section{OLS}

$\begin{array}{cc}\text { Long-run } & \text { Contemporaneous } \\ \text { response } & \text { response } \\ .75(.86) & 2.96(.48)\end{array}$

IV

$$
\begin{aligned}
& \text { Long-run } \\
& \text { response } \\
& -.26(.95)
\end{aligned}
$$

Note: Annual two-digit and four-digit data, 1958-1984 (Bartelsman and Gray, 1994). Response of sectoral productivity to a unit innovation in aggregate output. Instruments are the political party of the president and the rate of growth of military expenditure and the oil price, current and lagged once and twice. The standard errors of the impulse responses are estimated following Luetkepohl (1991). 


\begin{tabular}{|c|c|c|}
\hline \multicolumn{3}{|c|}{$\begin{array}{c}\text { Table } 4 \\
\text { PRODUCTION-FUNCTION REGRESSION } \\
\text { EOUATION (7): }\end{array}$} \\
\hline \multicolumn{3}{|c|}{$\Delta y_{t}=\theta_{1} \Delta h_{t}+\theta_{2} \Delta h_{t-1}+\theta_{3} \Delta k_{t}+\theta_{4} \Delta k_{t-1}+\theta_{5} \Delta m_{t}+\theta_{6} \Delta m_{t-1}+\sum_{i=0}^{2} \varphi_{j} \Delta y_{A, t-j}+u t$} \\
\hline & OLS & IV \\
\hline$\theta_{1}$ & $.26(.007)$ & $.31(.012)$ \\
\hline$\theta_{2}$ & $-.01(.007)$ & $-.03(.012)$ \\
\hline$\theta_{3}$ & $.03(.014)$ & $-.02(.023)$ \\
\hline$\theta_{4}$ & $-.01(.009)$ & $-.02(.016)$ \\
\hline$\theta_{5}$ & $.61(.006)$ & $.60(.010)$ \\
\hline$\theta_{6}$ & $-.01(.006)$ & $-.02(.001)$ \\
\hline$\varphi_{1}$ & $.18(.013)$ & $.16(.018)$ \\
\hline$\varphi_{2}$ & $-.06(.014)$ & $.05(.028)$ \\
\hline$\varphi_{3}$ & $-.01(.014)$ & $-.07(.035)$ \\
\hline \multicolumn{3}{|c|}{ Test of model restrictions } \\
\hline$H_{0}: \sum_{j=0}^{2} \varphi_{j}=0$ & 132.3 (s. lev. $=.00)$ & $37.1(\mathrm{~s}$. lev. $=.00)$ \\
\hline$H_{0}: \sum_{j=1}^{6} \theta_{j}=0$ & 57.7 (s. lev. $=.00)$ & $19.6($ s. lev. $=.00)$ \\
\hline \multicolumn{3}{|c|}{$\begin{array}{l}\text { Note: Annual four-digit data, 1958-1984 (Bartelsman and Gray, 1994). Standard errors are } \\
\text { reported in parentheses. Instruments are the political party of the president and the rate of } \\
\text { growth of military expenditure and the oil price, current and lagged once and twice. }\end{array}$} \\
\hline
\end{tabular}

